\title{
Investigating the Effects of Mitigation Techniques on Residual Stress and Microstructure of HSLA Welds
}

\author{
Houman Alipooramirabad ${ }^{1, a}{ }^{*}$, Reza Ghomashchi ${ }^{1, b}$, Anna Paradowska ${ }^{2, c}$ \\ and Mark Reid ${ }^{2, d}$ \\ ${ }^{1}$ School of Mechanical Engineering, the University of Adelaide, SA 5005, Australia
}

${ }^{2}$ Bragg Institute, Australian Nuclear Science and Technology Organisation (ANSTO), Lucas

Heights, NSW 2234, Australia

ahouman.alipooramirabad@adelaide.edu.au, breza.ghomashchi@adelaide.edu.au, canp@ansto.gov.au, ${ }^{d}$ markr@ansto.gov.au

Keywords: Microstructural Characterization, HSLA Welds, Neutron Diffraction, PWHT, Residual Stress

\begin{abstract}
Post-weld heat treatment is often required for pressure vessel and piping components for relaxing residual stresses and increasing the resistance to brittle fracture. The present study employed neutron diffraction to examine the effects of conventional post-weld heat treatment (PWHT) on the residual stresses in multi-pass, high-strength, low-alloy-steel, weld joints made by combined Modified Short Arc Welding (MSAW) and Flux Cored Arc welding (FCAW) processes. Residual stresses in excess of yield strength were developed in the Heat Affected Zone (HAZ) and the weld metal of the as-welded specimen (particularly the upper layers of the weld) which were reduced significantly as a result of applying PWHT. Also PWHT lead to substantial changes in the microstructural characteristics of high-strength, low-alloy-steel welds.
\end{abstract}

\section{Introduction}

Post-weld heat treatment (PWHT) is a stress relieving process where a uniform heating is applied at subcritical temperatures for a specified period of time until the desired stress relief is attained. The selection of the subcritical temperature is dependent on the alloy chemistry while the soaking time is thickness related [1]. In order to confirm the success of PWHT, an analysis of the microstructure and remaining residual stresses along with some basic mechanical testing is mandatory. An inappropriate stress relief heat treatment could lead to increasing residual stresses, distortion and degradation of the microstructure due to precipitation of carbides and resultant embrittlement [2]. Furthermore, from an economical view point, it is important to know if the annealing time is either too long (higher energy consumption) or unnecessarily short.

So far several experimental and numerical investigations have been carried out on the comparison of residual stress levels before and after PWHT. Paddea, et al. [3] used the neutron diffraction method to measure the residual stress distributions in a P91 steel-pipe girth weld before and after PWHT. They reported peak tensile residual stresses dropping from $600 \mathrm{MPa}$ to $120 \mathrm{MPa}$ after reheating to $750^{\circ} \mathrm{C}$ during PWHT. Smith and Garwood [4], using the more classic method of hole drilling, have reported a similar finding in a submerged-arc weldment in a $50 \mathrm{~mm}$ thick ferritic steel. They found significant reduction from $740 \mathrm{MPa}$ to $140 \mathrm{MPa}$ following PWHT. Cho, et al. [5] developed a 2D, thermal-elastic-plastic, finite-element model to evaluate the residual stresses for the as-welded condition and after PWHT. It was found that maximum residual stress for K- and V-type weld joints of thick plates were 316 and $256 \mathrm{MPa}$, respectively, which were reduced to 39.3 and 3.7 $\mathrm{MPa}$. Mitra, et al. [6] developed experimentally validated, finite-element models to investigate the effects of temperature and time on the relieving of residual stresses after PWHT for $800 \mathrm{~mm}$ thick

(c) (1) Content from this work may be used under the terms of the Creative Commons Attribution 3.0 license. Any further distribution of this work must maintain attribution to the author(s) and the title of the work, journal citation and DOI. Published under license by Materials Research Forum LLC. 
steel weldment. Rapid decrease of residual stresses during the initial stages of holding time at the PWHT temperature was found. Moreover, it was found holding temperature had a significant role on the relief of residual stresses, particularly when the PWHT is carried out at relatively lower temperatures. Yu, et al. [7] investigated the effects of PWHT on microstructural and mechanical properties in laser welds of GH3535 superalloy. An increase of up to $90 \mathrm{MPa}$ in the tensile strength of the joints was found after the PWHT at $871{ }^{\circ} \mathrm{C}$ for $6 \mathrm{~h}$, which was exceeding the strength of the original state of the base metal. The increase in the tensile strength of post-weld heat treated joints was found to be related with Mo-Si-rich, M6C-type carbides which were observed at solidification grain boundaries and solidification subgrain boundaries.

As briefly mentioned here, there is no report to examine the effects of PWHT on residual stress and microstructure of high-strength, low-alloy steel (HSLA) welds. Also the underlying mechanism of relaxation of residual stresses during PWHT process has not been identified. The current study is therefore carried out to characterize the PWHT process with respect to microstructure and residual stresses of the welded joint for multi-pass welds. In this paper we present comparative results of microstructural and residual stress measurements for the specimens in the as-welded condition and after successful PWHT.

\section{Experimental procedure}

\section{Details of weld deposition procedure}

The test specimens comprised two $20 \mathrm{~mm}$ thick steel plates (API 5L grade X70) with the dimensions of 250x200 $\mathrm{mm}^{2}$. Two samples were fabricated, one sample was used to measure the lattice spacing $\left(\mathrm{d}_{0, \mathrm{hkl}}\right)$ in the stress free mode and the other sample was used to evaluate the residual stresses for the as-welded condition and after the PWHT process. The yield strength of the parent metal is 490-520 $\mathrm{MPa}$ while the yield strength of the weld metal is about $545 \mathrm{MPa}$.

\section{Microstructural analysis}

The welded specimens were sectioned transversely and ground and polished down to $1 \mu \mathrm{m}$ diamond paste for metallographic analysis of the weld metal (WM), the heat-affected zone (HAZ) and parent metal (PM). For microstructural analysis, the samples were etched in 5\% Nital (5\% nitric acid in ethanol) or prepared by a double etching procedure using $2 \%$ Picral (2\% picric acid in ethanol) and $2 \%$ Nital (2\% nitric acid in ethanol) solutions. An Axio Zeiss optical microscope and an SEM QUANTA 450 were used to examine the microstructure of the WM, HAZ and the PM. Also transmission electron microscopy (TEM) analysis was carried out to fully characterize the morphology of the microstructure, precipitates and dislocations in different regions of the weld. TEM sample preparation was carried out using focused Ion beam (FEI Helios Nanolab 600-SEM) at the Adelaide microscopy centre.

\section{Neutron diffraction}

Neutron diffraction measurements were performed at the Australian Nuclear Science and Technology Organization (ANSTO) using the KOWARI strain scanner. Details of the procedure can be found elsewhere $[8,9]$. To perform strain measurements for the as-welded material and after PWHT, a $3 \times 3 \times 3 \mathrm{~mm}^{3}$ gauge volume was used. The Si (400) type double focusing monochromators generated a neutron beam with the wavelength of $1.67 \AA$. A detector angle, $2 \theta$, was set at $90^{\circ}$ corresponding to the $\alpha \mathrm{Fe}$ (211) diffraction peak.

\section{Results and discussion}

\section{Residual stress}

Fig.1 (a) and (b) show the longitudinal, transverse and normal residual stresses for the as-welded specimen. Tensile residual stress in excess of the yield strength of both the weld and parent metal was found at the depth of $3 \mathrm{~mm}$ from the weld surface and in the weld centreline for the as-welded 
specimen. The high tensile residual stress (longitudinal) at this region may be due to the fact that this is the last and final weld pass deposited and therefore the weld material could not have benefited from the tempering effect that previous passes had as the following pass was deposited. Therefore, thermal distribution is less uniform within this region as on one side the last pass is in contact with the already deposited passes and on the other side the heat is directly dissipated into the air. The formation of columnar grains is an indication of directional cooling of the last pass.

However as the depth of measurement increases (10 mm below the top surface) a decrease in the magnitude of residual stresses can be found due to tempering effects. The distribution of residual stresses across the weld after PWHT is shown in Fig. 2 (a) and (b). These data clearly reveal a substantial reduction in the magnitude of residual stresses after applying PWHT with a maximum of $142 \mathrm{MPa}$ which is approx. $26 \%$ of the yield strength of the weld metal.
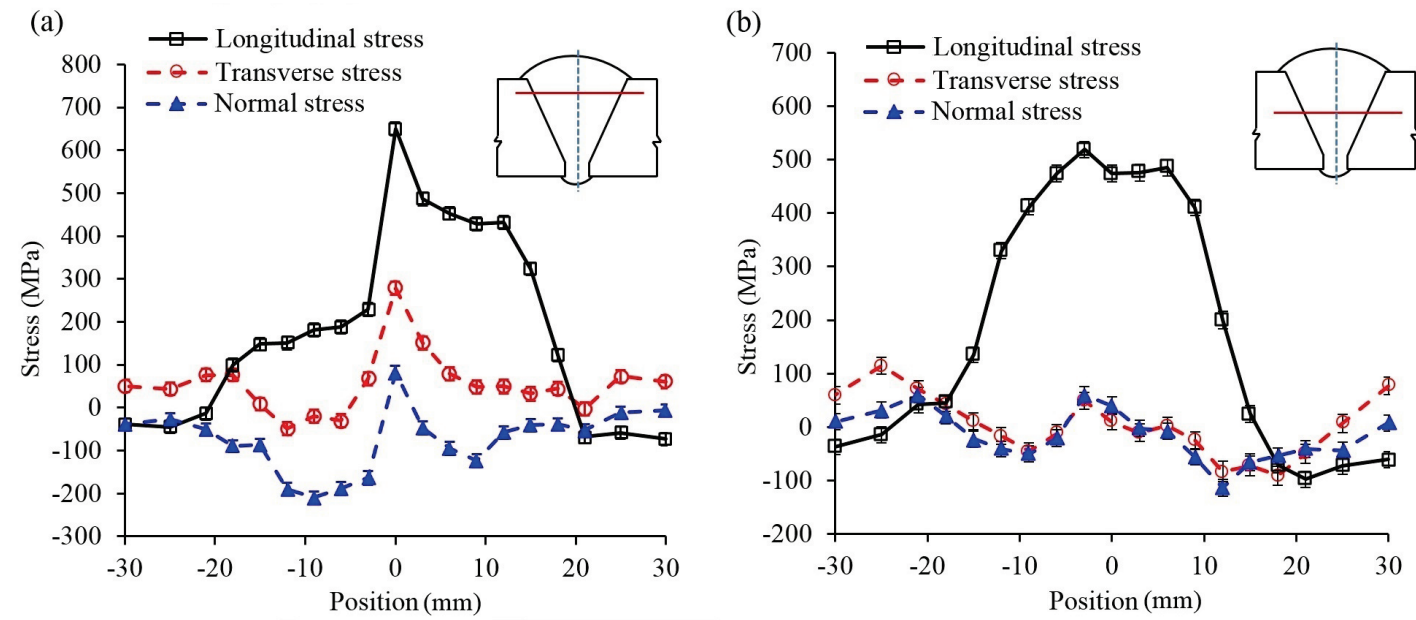

Fig. 1: Residual stress measurements for the as-welded specimen: (a) $3 \mathrm{~mm}$ from the top surface; (b) $10 \mathrm{~mm}$ from the top surface.
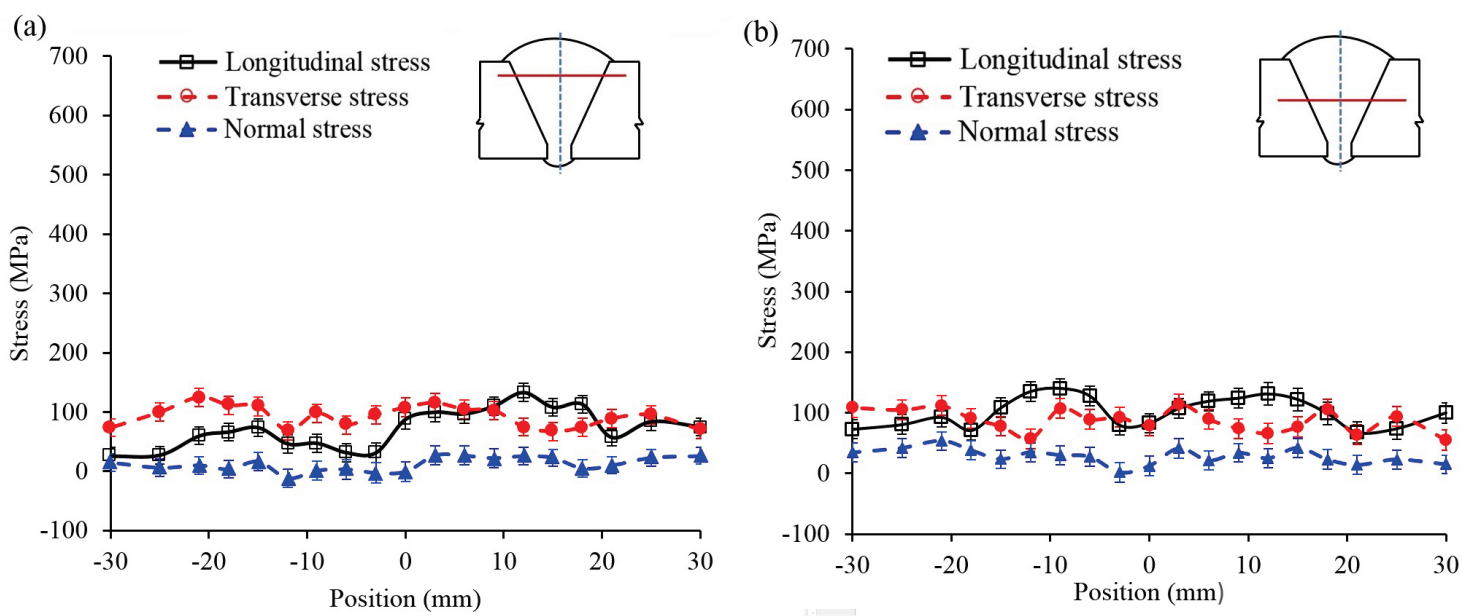

Fig.2: Residual stress measurements after PWHT: (a) $3 \mathrm{~mm}$ from the top surface; (b) $10 \mathrm{~mm}$ from the top surface. 


\section{Microstructural analysis}

Fig.3 provides representative microstructures of the Coarse-Grain Heat-Affected Zone (CGHAZ, close to the fusion zone), for as-welded and post-weld heat treated specimens, examined in this work. The as-welded specimen however, contains Widmanstätten ferrite, bainite and polygonal ferrite but still is a mainly acicular ferritic weld [8]. While due to tempering effects in PWHT resulted in grain growth and coarsening of the microstructure, mainly equiaxed polygonal ferrite was found. It can also be seen that the microstructure in the CGHAZ is more homogeneous in terms of grain size after the PWHT process. In order to fully characterize the microstructure of the as-welded and post-weld heat treated specimens, TEM analysis was carried out. The TEM micrographs in Fig.4, which were taken from the weld centreline in the as-welded sample and after PWHT, clearly demonstrate the effect of thermal treatment on the rearrangement of dislocations and the formation of sub-grain boundaries. It is widely accepted that dislocation climb, a thermally activated process, is a prerequisite for sub-grain formation during creep of metal and alloys. Therefore existing sub-grains for the post-weld heat treated specimens, as shown in Fig. 4, indicate the dislocation climb and as a result, the development of creep strain during PWHT as a driving mechanism behind residual stress relaxation, which is in line with previous reports $[10,11]$.

(a)

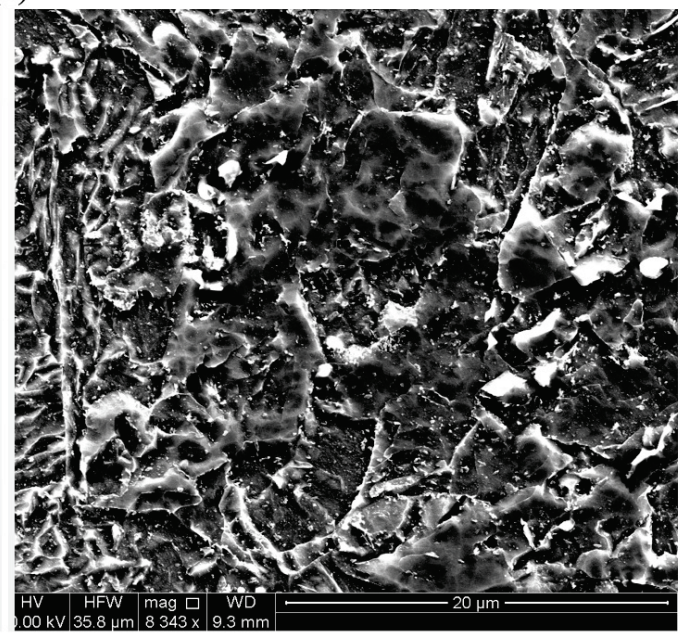

(b)

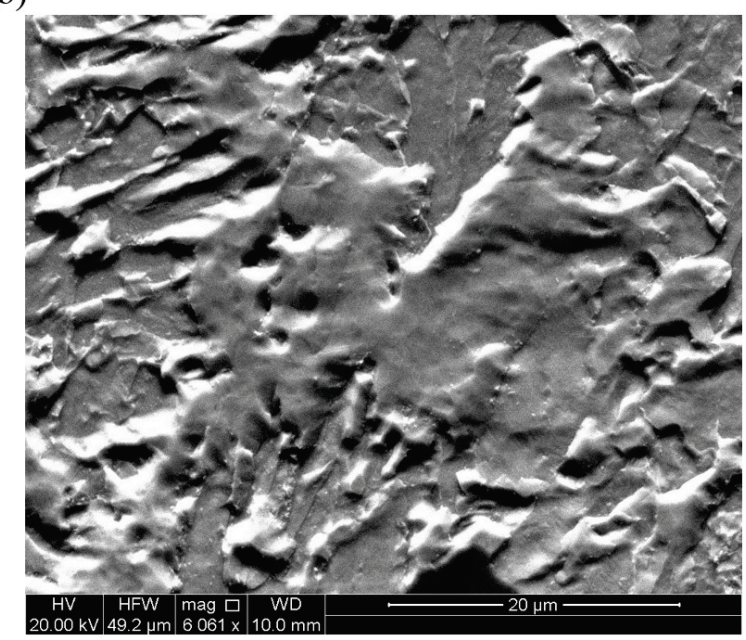

Fig.3: SEM micrographs showing the CGHAZ in the weld centreline in both (a) as-welded and (b) post-weld heat treated specimens.

\section{Conclusions}

The key findings of this experimental study were:

- The magnitude of the residual stresses decreased substantially after PWHT (about 26\% of yield strength of the weld metal in the longitudinal direction and $20 \%$ in the transverse direction).

- High temperature leads to microstructural changes and an increase in the dislocation mobility, assisting dislocation climb and diffusion. This supports the creep-strain-induced, stress-relaxation mechanism during PWHT and explains the decrease of residual stress in the PWHT specimen. 
(a)

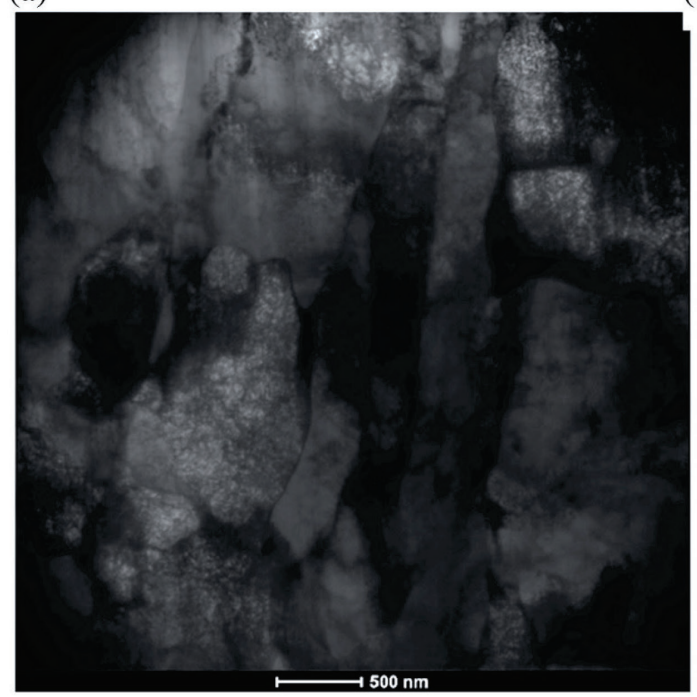

(b)

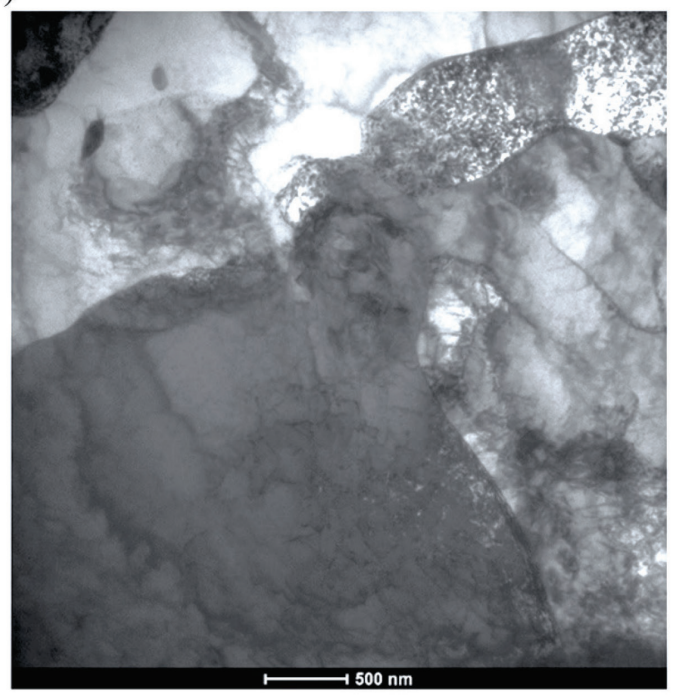

Fig.4: TEM micrographs showing the weld metal in (a) as-welded and (b) post-weld heat treated specimen.

\section{Acknowledgments:}

This work was conducted with the assistance of an Australian Nuclear Science and Technology Organisation (ANSTO) facilities access award (Award No. 4591). The welding was carried out at AWS. We would like to acknowledge with gratitude the support of Mr. Neville Cornish and Ashley Blanchard from AWS and Mr Pascal Symons at Adelaide University.

\section{References}

[1] Olabi A-G. Residual stresses and heat treatments for metallic welded components: Dublin City University; 1994.

[2] Aloraier A, Ibrahim R, Ghojel J. Eliminating post-weld heat treatment in repair welding by temper bead technique: role bead sequence in metallurgical changes. Journal of Materials Processing Technology. 2004;153:392-400. http://dx.doi.org/10.1016/j.jmatprotec.2004.04.383

[3] Paddea S, Francis JA, Paradowska AM, Bouchard PJ, Shibli IA. Residual stress distributions in a P91 steel-pipe girth weld before and after post weld heat treatment. Materials Science and Engineering: A. 2012;534:663-672. http://dx.doi.org/10.1016/j.msea.2011.12.024

[4] Smith DJ, Garwood SJ. Influence of postweld heat treatment on the variation of residual stresses in $50 \mathrm{~mm}$ thick welded ferritic steel plates. International Journal of Pressure Vessels and Piping. 1992;51:241-256. http://dx.doi.org/10.1016/0308-0161(92)90083-R

[5] Cho JR, Lee BY, Moon YH, Van Tyne CJ. Investigation of residual stress and post weld heat treatment of multi-pass welds by finite element method and experiments. Journal of Materials Processing Technology.

http://dx.doi.org/10.1016/j.jmatprotec.2004.04.325

2004;155-156:1690-1695.

[6] Mitra A, Siva Prasad N, Janaki Ram GD. Influence of Temperature and Time of Post-weld Heat Treatment on Stress Relief in an 800-mm-Thick Steel Weldment. Journal of Materials Engineering and Performance. 2016;25:1384-1393. http://dx.doi.org/10.1007/s11665-016-1995-6 
[7] Yu K, Jiang Z, Leng B, Li C, Chen S, Tao W, Zhou X, Li Z. Effects of post-weld heat treatment on microstructure and mechanical properties of laser welds in GH3535 superalloy. Optics \& Laser Technology. 2016;81:18-25. http://dx.doi.org/10.1016/j.optlastec.2016.01.029

[8] Alipooramirabad H, Ghomashchi R, Paradowska A, Reid M. Residual stress- microstructuremechanical property interrelationships in multipass HSLA steel welds. Journal of Materials Processing Technology. 2016;231:456-467. http://dx.doi.org/10.1016/j.jmatprotec.2016.01.020

[9] Alipooramirabad H, Paradowska A, Ghomashchi R, Kotousov A, Reid M. Quantification of residual stresses in multi-pass welds using neutron diffraction. Journal of Materials Processing Technology. 2015;226:40-49. http://dx.doi.org/10.1016/j.jmatprotec.2015.07.002

[10] Dong P, Song S, Zhang J. Analysis of residual stress relief mechanisms in post-weld heat treatment. International Journal of Pressure Vessels and Piping. 2014;122:6-14. http://dx.doi.org/10.1016/j.ijpvp.2014.06.002

[11] Zhang J, Dong P, Song S. Stress Relaxation Behavior in PWHT of Welded Components. ASME 2011 Pressure Vessels and Piping Conference: American Society of Mechanical Engineers; 2011. p. 673-679. http://dx.doi.org/10.1115/pvp2011-57826 